\title{
Relationships between landslides and land use changes in the Sanbagawa and Mikabu Belts, Shikoku, Japan
}

\author{
Roxanne Lai ${ }^{\text {a, *, Takashi Oguchi }}{ }^{\text {a, b }}$ \\ a Graduate School of Frontier Sciences, The University of Tokyo, 5-1-5 Kashiwanoha Kashiwa, Chiba 277-8561, Japan \\ ,roxanne.lai@s.k.u-tokyo.ac.jp,oguchi@csis.u-tokyo.ac.jp \\ ${ }^{b}$ Center for Spatial Information Science, The University of Tokyo, 5-1-5 Kashiwanoha Kashiwa, Chiba 277-8568, Japan \\ * Corresponding author
}

Keywords: Land use changes, Landslides, Vegetation, Shikoku

\begin{abstract}
:
Changing land use is an increasingly important issue as human habits, behaviors, and needs change. There has been an increase in land and agricultural abandonment in some places of the world. In Japan, movement of the population from rural to urban areas have resulted in much land and agricultural abandonment. In 2016, a land ministry survey showed that 4.1 million hectares of land in Japan had unclear ownership, with farmland making up $16.9 \%$ of the total. As vegetation cover changes after land abandonment, this temporal and spatial effect may have important effects on geomorphic processes such as landslide susceptibility and landslide kinematics.
\end{abstract}

Here we track long-term land use changes over vegetated landslide areas of the Sanbagawa and Mikabu Belts of Shikoku Island, Japan. The Sanbagawa and Mikabu Belts are metamorphic belts that run across Southwest Japan, and are home to numerous large crystalline schist landslides, including the widely-studied slow but continuously moving Zentoku landslide. Villages and communities have been built on these landslide areas due to historical and cultural factors, as well as the fertility of the soil. Consequently, given the changing land uses including land abandonment in these landslide areas over time, we use long-term high-resolution land cover vegetation datasets to examine first the long-term land use changes, and then use statistical methods to explore their relationships with landslide susceptibility and kinematics. Mapping of spatial data and their analysis using GIS constitute a core part of the research. The results suggest interconnections between land use changes and land movement. 